\title{
Bumblebee inquilinism in Bombus (Fernaldaepsithyrus) sylvestris (Hymenoptera, Apidae): behavioural and chemical analyses of host-parasite interactions ${ }^{1}$
}

\author{
Stéphanie DRONNET ${ }^{\mathrm{a}, \mathrm{b} *}$, Xavier SIMON $^{\mathrm{b}}$, Jean-Claude VERHAEGHE, ${ }^{\mathrm{b}}$, \\ Pierre RASMONT ${ }^{\mathrm{b}}$, Christine ERRARD ${ }^{\mathrm{a}}$ \\ a Institut de Recherche sur la Biologie de l'Insecte, UMR CNRS 6035, Faculté des Sciences et Techniques, \\ Université François Rabelais, 37200 Tours, France \\ b Laboratoire de Zoologie, Université de Mons-Hainaut, 19 avenue Maistriau, 7000 Mons, Belgium \\ c Laboratoire de l'Environnement, Université Libre de Bruxelles, 81 rue de la Gare, 5670 Treignes, Belgium
}

Received 29 January 2004 - Revised 7 May 2004 - Accepted 2 June 2004

Published online 16 March 2005

\begin{abstract}
The bumblebee Bombus sylvestris is an obligate social inquiline of B. pratorum and nestinvading females are known to integrate themselves into host colonies, usually without any aggression. We investigated whether cuticular compounds could be involved in discrimination processes in common bumblebees, and whether they play a role in the social integration of inquilines in host nests. We tested nestmate recognition in B. terrestris workers, and analysed cuticular chemical profiles of hairs taken from allocolonial individuals. Bumblebees belonging to the same colony shared a common odour. Then, we investigated how $B$. sylvestris females integrated into colonies of natural and non-natural hosts, $B$. pratorum and B. terrestris, respectively. Inquiline females apparently succeeded in entering a host colony by expressing non-aggressive behaviours and had no chemical signature; subsequently, acquisition of a chemical signature similar to the host colony might facilitate their integration into the host nest.
\end{abstract}

Bombus sylvestris / inquilinism / discrimination process / chemical signature / non-aggressive strategy

\section{INTRODUCTION}

In Hymenoptera, social parasites infiltrate into host colonies and take advantage of their resources (Kistner, 1979; Wcislo, 1987). Obligate social parasites produce sexual offspring only, and depend on host workers for all other resources (Wilson, 1971). In bumblebees, all species of the formerly named Psithyrus group have an obligatory dependence upon their respective Bombus host colonies and are called "cuckoo bumblebees" (Wilson, 1971; Alford, 1975; Williams, 1998; Michener,
2000). Inquilines enter the host nests, remain there and replace functionally or kill the host queen. Then, workers rear offspring of the inquiline females because the latter cannot produce wax and lack the pollen-collecting apparati on their posterior tibiae, indicating that they cannot collect pollen to feed their offspring.

Social parasites and hosts of social Hymenoptera are sometimes closely related species. This is typically in accordance with the Emery's rule (Emery, 1909), which proposes speciation patterns to explain how the

\footnotetext{
* Corresponding author: dronnet@univ-tours.fr

${ }^{1}$ Manuscript editor: Marla Spivak
} 
parasites and their hosts would have evolved jointly (Schmid-Hempel, 1998; Lowe et al., 2002). If Emery's rule was applied for bumblebees, one species of inquiline should be phylogenetically close to its host species. In contrast, the bumblebee obligate inquiline species form several subgenera constituting a distinct and monophyletic clade within the group of Bombus, only partly comprising the corresponding host species (Löken, 1984; Williams, 1994, 1998; Michener, 2000; Rasmont et al., 1995; Pedersen et al., 1996; Schwarz et al., 1996). This statement calls into question how inquiline females manage to be accepted by distantly related hosts?

The process of colony usurpation in Bombus inquilines appears to be highly variable. It generally starts with the parasitic female that discriminates between potential host species on the basis of individual and nest odours (Cederberg, 1979, 1983; Fisher, 1983a, 1985). These chemical cues emanate from the Dufour's gland and the terminal tergal segments of their hosts (Fisher et al., 1993). In workers of some bumblebee species, Oldham and collaborators (1994) found a close correspondence in composition between the hydrocarbons of the Dufour gland and the cuticular hydrocarbons. Once a female enters a host nest, the process of integration seems to depend upon the species involved. While some inquilines passively usurp host colonies (Küpper and Schwammberger, 1995), others aggressively maul their hosts to establish dominance (Van Honk et al., 1981; Fisher, 1984, 1988). A recent study showed that nest-invading Bombus (Psithyrus) norvegicus females may use allomones to defend themselves against attacking B. (Pyrobombus) hypnorum host workers (Zimma et al., 2003). These parasitic females may also ensure that they secure a colony's reproductive resources by eating the host queen's eggs (Fisher, 1987) and by suppressing the ovarian development of workers (Fisher, 1984; Vergara et al., 2001). However, other species cohabitate with the host queen and do not interfere with worker development (Fisher, 1983b).

While the fundamental mechanisms of inquilinism are known for other social Hymenoptera (see Bagnères et al., 1996 for wasps; Lenoir et al., 2001 for a review), further studies are needed to clarify the process in
Bombus, in which there are a diversity of mechanisms for usurpation and integration of parasites. We wanted to clarify whether cuticular compounds could be involved in the recognition system in bumblebee colonies, and so in the usurpation of a host colony by an inquiline female. Indeed, colonial identity for most social insects is caused by nestmate recognition that is believed to be mediated by cuticular substances, mostly hydrocarbons (Free, 1958, 1987; for reviews see Van der Meer and Morel, 1998; Lenoir et al., 1999). Each colony member possesses its own cues that are correlated with genotype and transferred among workers forming the colony odour.

The aim of the present work was to investigate how the inquiline B. sylvestris females could integrate into their host colony. To demonstrate bumblebee discrimination processes, we displayed social cohesiveness in different B. terrestris colonies first by performing behavioural tests and analysing worker cuticular chemical cues. Then, we compared the invasion behaviours of the inquiline $B$. sylvestris given access to two potential hosts: $B$. pratorum, its natural host, and B. terrestris, a distantly related species that is rarely used as a host in nature. We also compared the chemical profiles of $B$. sylvestris and $B$. terrestris to obtain more precise information on the mechanisms involved in parasite usurpation.

\section{MATERIALS AND METHODS}

\subsection{Biological material}

We studied the behaviours of Bombus (Fernaldaepsithyrus) sylvestris (Lepeletier) exposed to its natural host, B. (Pyrobombus) pratorum (L.) and to a non-natural host, B. (Bombus) terrestris (L.), which is normally invaded by $B$. (Ashtonipsithyrus) vestalis (Fourcroy).

Queens of B.terrestris $(\mathrm{n}=117)$ were fieldcaught in the vicinity of Mons (Belgium) from March to May 2000, and kept individually in wooden nest boxes $(12 \times 12 \times 10 \mathrm{~cm})$ in a climate room at $28{ }^{\circ} \mathrm{C} \pm 1{ }^{\circ} \mathrm{C}$ and $75 \% \mathrm{RH}$. Queens and their offspring were fed ad libitum with sugar water and pollen. Two of the $B$. terrestris colonies reared this way $(\mathrm{Bt} 1, \mathrm{Bt} 3)$ were placed in an observation nest $(19 \times 15 \times 10 \mathrm{~cm})$ connected to the outside environment by a tube for free foraging: they were used as host nests for intrusion tests (see below). Four other 


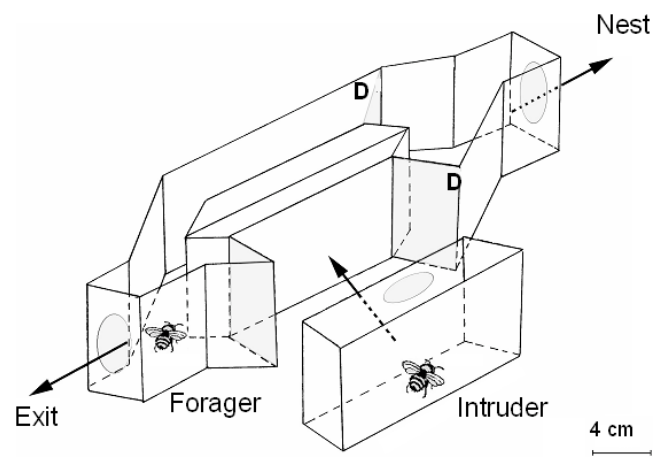

Figure 1. The "intrusion room": to introduce an individual (from the same colony or not) into the connected nest. The two doors (D) could be opened or closed according to the step of experiments.

colonies (Bt2, Bt4, Bt5, Bt6) were transferred into environmentally isolated nests and used for the dyadic encounters experiments. Because field collected $B$. pratorum queens repeatedly failed to found colonies under the same laboratory conditions as $B$. terrestris, B. pratorum workers were caught from the same natural area (from May to June 2000), and kept together in wooden nest boxes at room temperature, and used in the experiments. Thirteen females of the inquiline B. sylvestris were caught in forests of Ardennes (Belgium) in April and May 2000 while exhibiting nest searching behaviours. They were maintained in wooden cages $(24 \times 12 \times 10 \mathrm{~cm})$ at room temperature and fed regularly with sugar water and pollen until they were used in the experiments.

\subsection{Behavioural studies}

\subsubsection{Intrusion tests}

To observe the reaction of workers from a B. terrestris colony ( $\mathrm{Bt} 1$ or $\mathrm{Bt} 3$ ) to the entrance of an intruder, we created an "intrusion room" that would enable an invading worker or inquiline female to enter the nest without disturbing the foraging activity of workers (Fig. 1). This container had doors to control movement to and from the compartment and, like the nests, had wooden floors and plastic walls and lids. Prior to any introduction, the intruder was first cold-sedated to prevent any aggressive reactions to the manipulation. The female was then placed in the "intrusion room", isolated from the nest and the foragers. Less than one minute after the intruder awoke, the door into the nest was opened to allow invasion. The "intrusion room" was cleaned with ethanol between each experiment.
The different types of intrusions were: (1) homocolonial (reintroduction into the colony $\mathrm{Bt} 1$ of a nestmate belonging to the same colony), and (2) allocolonial (intrusion of a conspecific worker belonging to the colony $\mathrm{Bt} 2$ into the foreign colony $\mathrm{Bt} 1$ ). We counted the number of times an intruder was attacked during a 10 min period. Each experiment was replicated ten times. Each individual was used only once as an invader, and a minimum of 24 hours separated experiments to avoid any potential problems with pseudoreplication. The number of aggressive interactions was compared between (1) and (2) using a one-tailed binomial test (Siegel and Castellan, 1956). Moreover, we observed the intrusion of one $B$. sylvestris inquiline female into the $B$. terrestris colony $\mathrm{Bt} 3$ during four hours. We could perform only this one intrusion because of the low number of available specimens of the inquilines.

\subsubsection{Aggression tests}

The discriminatory abilities of bumblebees were tested in dyadic encounters between nestmates or alien individuals. The different types of encounters were: (1) homocolonial intraspecific (B. terrestris, same colony Bt4), (2) allocolonial intraspecific (B. terrestris, colonies $\mathrm{Bt} 4 / \mathrm{Bt} 5$ ), and (3) interspecific (B. terrestris Bt 4 / B. sylvestris). Each encounter took place in an arena (plastic box $18 \times 14.5 \times$ $3 \mathrm{~cm}$ ) either neutral (i.e. without comb), or non-neutral, i.e. having in the middle a $2 \mathrm{~cm}^{3}$ piece of comb from the Bt4 colony containing eggcups with larval clumps (under the wax layer). (4) Encounters were also carried out between $B$. sylvestris inquiline and $B$. pratorum workers to compare the interactions of the females towards non-natural (B. terrestris) and natural hosts (B. pratorum).

For the experiments, each 4-day-old bumblebee was individually marked and used only once in a given encounter to prevent familiarisation. Each type of encounter was replicated ten times, so seventy encounters were observed in total. We observed the behavioural interactions between two individuals removed from their nest, cold-sedated and placed in the arena by $15 \mathrm{~cm}$ under red lighting. Encounters began as soon as both of the individuals awoke, and their interactions were video-recorded for $10 \mathrm{~min}$. Between experiments, arenas were first cleaned with laboratory detergent, then with ethanol to remove any chemical marks.

The reactions noted were (a) non agonistic behaviours: selfgrooming, antennal contact given to the other bumblebee $[<1 \mathrm{~s}]$; (b) agonistic behaviours: buzzing [= humming as described by Duchateau (1989)], avoidance [= retreat as described by Van Honk et al. (1981)], threat as indicated by raising the mid-legs or rolling on the back to present the sting, and attack [attempt of biting and/or stinging]. Alloccurrence sampling was used (Altmann, 1974). 
A one-tailed binomial test (Siegel and Castellan, 1956) was used to compare frequencies of the behaviours towards each encounter type.

\subsection{Cuticular chemical analysis}

The chemical profile of the cuticle was analysed for B. terrestris workers and B. sylvestris females. We could not analyse chemical profiles for $B$. pratorum workers because of trouble in rearing colonies of this species. Instead of using the classical method of cuticular chemical extraction that kills the insect sampled, a new method was employed to keep the individuals alive. A given quantity of thorax hairs (around 50 hairs) was removed from the dorsal side (thorax) of five sedated workers from colonies Bt1 through Bt5 prior to any experimental tests to avoid possible contamination. The B. sylvestris inquiline introduced into colony Bt 3 had hairs sampled before intrusion, then 3 hours and 19 hours after intrusion. Additional samples were taken from eight B. sylvestris females prior to and following their being individually placed in a mesh cage that was inserted near the colony comb of colony Bt6 for $24 \mathrm{~h}$. These inquilines had access to sugar water and the mesh enabled them to be in contact with comb but protected from any attack of the resident workers. The hairs of eight workers belonging to the colony Bt6 were sampled before the introduction of the first inquiline.

The compounds on hairs of each individual were extracted by immersion in $1 \mathrm{ml}$ of dichloromethane for ten minutes. The extract was evaporated and kept dry at $-20{ }^{\circ} \mathrm{C}$ prior to analysis. An internal standard, eicosane $\left(n \mathrm{C}_{20}\right)$, was added to each extract to calibrate and quantify the different compounds. Extracts were redissolved in $50 \mu \mathrm{L}$ of dichloromethane, of which $1 \mu \mathrm{L}$ was injected into a Varian 3300 gas chromatograph with a flame ionisation detector equipped with a capillary column (Supelco CPSIL 5WCOT, $30 \mathrm{~m} \times 0.25 \mathrm{~mm}$ ID). The injector was an on-column type. The carrier gas was helium at 1 bar pressure, and the temperature was programmed to increase from $80{ }^{\circ} \mathrm{C}$ to $280{ }^{\circ} \mathrm{C}$ at $5{ }^{\circ} \mathrm{C} / \mathrm{min}$ with a final hold of $10 \mathrm{~min}$.

The cuticular compounds were identified by comparison to a previous report in B.terrestris (Oldham et al., 1994). For each profile the relative value of each peak with respect to the total was calculated and expressed as a percentage. Discriminant analysis was used to estimate the similarity between the chemical profiles of the different colonies and the inquilines.

Chemical compound profiles were also generated among those analysed before and after introduction into the $B$. terrestris colony (Bt6). Absolute concentrations of cuticular hydrocarbons were also calculated for five workers of colony Bt6 and five
B. sylvestris females prior to and 24 hours after the inquilines were introduced. The means of the total quantities of chemical compounds before and after introduction were compared using the Wilcoxon test. The means of the total quantities of chemical compounds were also compared between the $B$. terrestris workers and the $B$. sylvestris females after their introduction into colony Bt6 using the non-parametric Mann-Whitney U-test. The analysis was performed on 44 extracts, on 10 major peaks. All statistical analyses were performed using Statistica ${ }^{\odot}$ (Statsoft v. 5.1 for Windows).

\section{RESULTS}

\subsection{Behavioural studies}

\subsubsection{Intrusion tests}

In the intraspecific tests, the introduced workers of colony $\mathrm{Bt} 2$ were attacked significantly more often by resident workers of colony Bt1 than same-nest (homocolonial) control workers (89 and 3 attacks in total of replications respectively, $P<0.001)$. The control workers entered into the nest without being disturbed, and continued their tasks. In contrast, allocolonial workers hesitated before entering the nest, moved quickly on the comb to examine a few pollen cups, were repeatedly the targets of aggression and would leave the nest within $30 \mathrm{~min}$ from the time they were introduced.

The female B. sylvestris introduced into colony $B$. terrestris Bt3 was attacked quickly by resident workers but she tried to avoid them and did not defend herself immediately. Although she killed several workers in her own defence, the invader tried to use evasion as her primary strategy in the foreign colony.

\subsubsection{Aggression tests}

\subsubsection{Encounters of B. terrestris with $B$. terrestris and B. sylvestris in a neutral arena}

In all homocolonial encounters (control), the interactions among nestmate individuals were not aggressive (Fig. 2). The intraspecific confrontations between individuals belonging to two different colonies resulted in a higher 


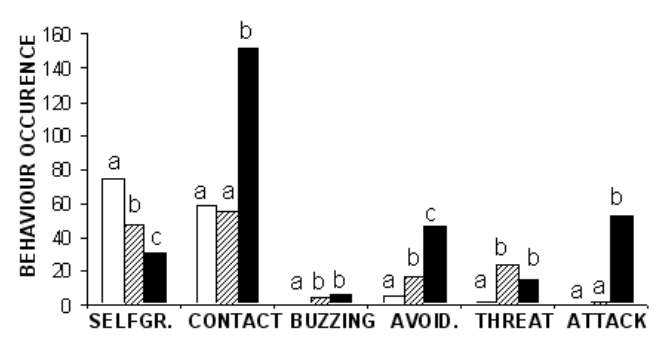

Figure 2. Comparison between behavioural reactions of $B$. terrestris workers towards homocolonial workers (white), allocolonial workers (hatched) and B. sylvestris inquiline females (black). "Avoid." = "avoidance", "Selfgr." = "selfgrooming" (10 replicates; Binomial test; $P<0.05$; different letters represent the groups that differed significantly).

frequency of agonistic behaviours (buzzing: $P<0.05$, avoidance: $P<0.01$; threat: $P<0.001$ ), but there was no significant difference for attack behaviours. In contrast, $B$. terrestris workers alternatively avoided and attacked $B$. sylvestris females significantly more often $(P<0.001)$ than nestmate and non-nestmate conspecifics. Brief antennal contacts towards $B$. sylvestris were more frequent $(P<0.001)$ than that noted in all intraspecific encounters. Moreover selfgrooming was less frequent when workers were in presence of the inquiline $(P<0.001)$.

\subsubsection{Influence of comb on behavioural interactions}

Because the video observations of antennal contact directed to the comb were difficult to distinguish from those of antennal contact among individuals, the latter behaviour was not recorded in non-neutral arenas. We focused on the agonistic behaviours.

In all homocolonial, intraspecific encounters in non-neutral arenas, no agonistic behaviour was observed. The nestmate workers spent most of their time moving about and examining the comb with their antennas and grooming themselves. In allocolonial encounters, workers also spent much of their time exploring the comb. They groomed themselves a lot, and were less frequently aggressive towards the non-nestmate workers than in the neutral arena (Fig. 3A). Only buzzing was observed at a higher frequency $(P<0.001)$. In contrast,

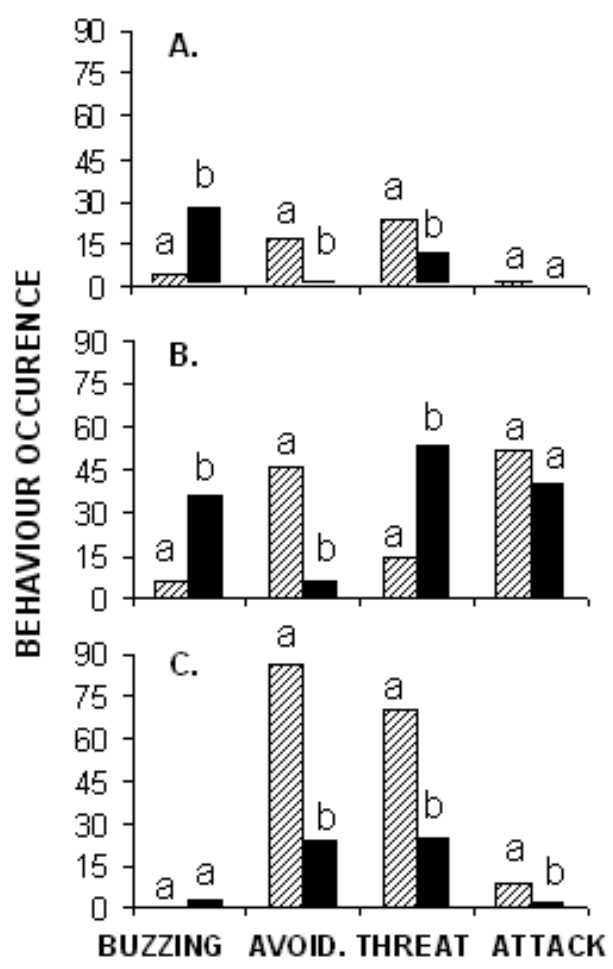

Figure 3. Comparison of behavioural reactions in absence (hatched) or in presence of comb (black) from B. terrestris $\mathrm{Bt} 4$ colony: B. terrestris $\mathrm{Bt} 4$ workers towards (A) allocolonial B. terrestris, (B) B. sylvestris inquilines, and (C) B. sylvestris inquilines towards $B$. terrestris Bt4 workers. "Avoid." = "avoidance" (10 replicates; Binomial test; $P<0.05$; different letters represent the groups that differed significantly).

host workers exposed to $B$. sylvestris inquilines buzzed and threatened significantly more often (Fig. 3B, $P<0.001$ ) in the presence of their colony comb than when in a neutral arena. The B. terrestris workers spent most of their time on the comb, so they did not meet the inquilines as often as in the neutral arena (e.g. lower frequency of avoidance, $P<0.001$ ). However, when the inquilines moved near the comb, the workers are always very aggressive.

The presence of a comb also affected the behaviours of B. sylvestris (Fig. 3C). In nonneutral arenas, the inquilines were significantly less aggressive towards B.terrestris 


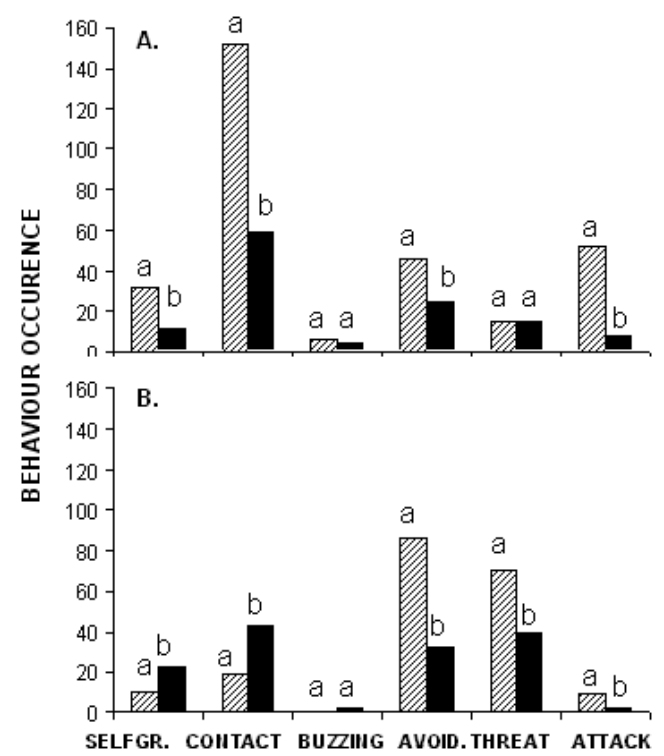

Figure 4. Comparison of behavioural reactions of (A) B. terrestris (hatched) and B. pratorum (black) towards $B$. sylvestris inquilines and (B) B. sylvestris inquilines towards $B$. terrestris (hatched) and towards B. pratorum (black). "Avoid." = "avoidance", "Selfgr." = "selfgrooming" (10 replicates; Binomial test; $P<0.05$; different letters represent the groups that differed significantly).

(threat, $P<0.001$; attack, $P<0.05$ ) and significantly less likely to avoid the workers $(P<$ 0.001). They also groomed themselves more often and exhibited the novel behaviour of rubbing the ventral side of their abdomen against the comb while they climbed the comb.

\subsubsection{Host specificity}

A comparison between the behavioural interactions of $B$. sylvestris with B. terrestris and $B$. pratorum workers in neutral arena encounters showed a clear difference in the way that the two host species dealt with the inquiline female. The B.terrestris workers interacted more often with the $B$. sylvestris than did B. pratorum, notably with regard to antennal contacts $(P<0.001)$ and agonistic behaviours (avoidance: $P<0.01$; attack: $P<$ 0.001 ) (Fig. 4A). B. sylvestris females were less frequently agonistic towards $B$. pratorum workers (avoidance, $P<0.001$; threat, $P<0.05$;

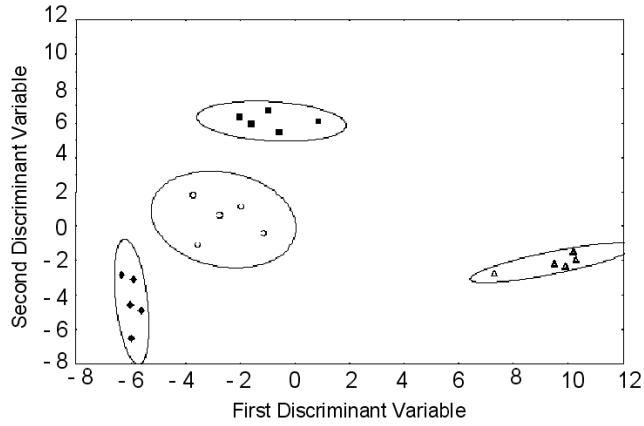

Figure 5. A plot of the first two principal variables in the discriminant analysis of chemical profiles of four $B$. terrestris colonies studied in behavioural experiments (Bt1, open triangles; Bt2, full diamonds; Bt4, open circles; Bt5, full squares). Each group is surrounded by the confidence ellipse $(P<0.05)$.

attack, $P<0.05)$ than towards $B$. terrestris (Fig. 4B), but engaged in more antennal contacts with the former species $(P<0.01)$.

\subsection{Cuticular chemical analysis}

The B.terrestris species possessed a species-specific chemical profile as Oldham et al. (1994) had previously described from GS-MS tests on wing, leg and antenna samples. We observed the same pattern in the chemical analysis of abdominal hairs, finding twenty peaks.

A first discriminant analysis was made for the four colonies (Bt1, Bt2, Bt4, Bt5) used in behavioural studies (Fig. 5). Colonies were clustered in four well separated groups $(100 \%$ well clustered, $\mathrm{F}=8.38, \mathrm{dl}=30,21 ; P<0.001)$. The first discriminant variable $(67 \%$ of variance) separated the colony Bt 1 from Bt2, Bt4 and $\mathrm{Bt} 5$ (respectively, $\mathrm{F}=19, P<0.001 ; \mathrm{F}=$ 4.92, $P<0.001 ; \mathrm{F}=4.47, P<0.05)$, the second discriminant variable ( $31 \%$ of variance) $\mathrm{Bt} 5$ from $\mathrm{Bt} 1, \mathrm{Bt} 2$ and $\mathrm{Bt} 4$ (respectively, $\mathrm{F}=126.56 ; \quad \mathrm{F}=16.86 ; \quad \mathrm{F}=19 ; \quad P<0.001)$. Our results indicated that $B$. terrestris workers could be separated according to their colony of origin on the basis of compositional variance in their cuticular compounds. Moreover chemical profiles of some larvae, pupae and wax samples of cocoons were similar to those of workers (unpublished data). 


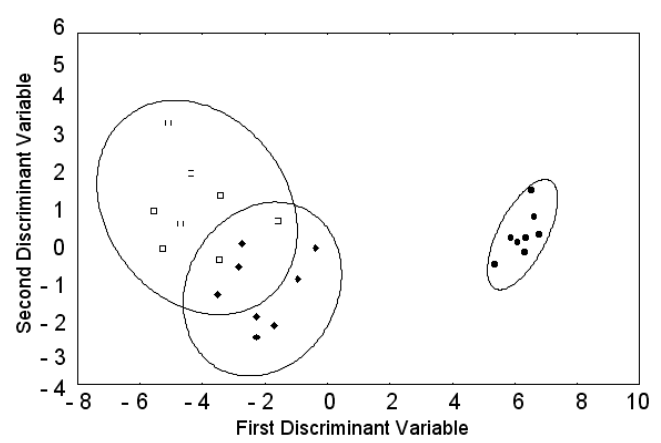

Figure 6. A plot of the first two principal variables in the discriminant analysis of chemical profiles of $B$. terrestris workers belonging to the host colony (Bt6; full circles), B. sylvestris inquilines before introduction into the $B$. terrestris colony Bt6 (open squares), and B. sylvestris inquilines 24 hours after introduction (full diamond). Each group is surrounded by the confidence ellipse $(P<0.05)$.

The cuticular hairs of B. sylvestris females had a profile corresponding to B.terrestris host species, but contained few chemical cues before introduction into Bt6 colony. Twentyfour hours after their introduction into Bt6, these compounds were found in greater quantities. The discriminant analysis (Fig. 6) showed that the individuals were clustered forming three distinct groups: B. terrestris workers, $B$. sylvestris before introduction into the host nest, and B. sylvestris 24 hours after $(\mathrm{F}=3.47 ; \mathrm{dl}=28,13 ; P<0.01)$. The first discriminant variable ( $95 \%$ of variance) separated the chemical profiles of the $B$. terrestris workers from those of the $B$. sylvestris before and after introduction (respectively: $\mathrm{F}=11.88$, $P<0.001 ; \mathrm{F}=7.81, P<0.01)$. While the two $B$. sylvestris groups were visually separated on the graph, they were not significantly different $(\mathrm{F}=1.07, P=0.48)$. The total quantity of cuticular chemicals in B. sylvestris females increased from $141.3 \pm 5.4 \mathrm{ng} / \mathrm{extract}$ before and $302.6 \pm 29.9 \mathrm{ng} / \mathrm{extract}$ after introduction $(P<0.05)$. This larger quantity of compounds on B. sylvestris females 24 hours after their introduction was quite similar to the quantity extracted from B.terrestris host workers $(312.5 \pm 24.0 \mathrm{ng} / \mathrm{extract} ; \quad P=0.75)$. Similar increases were observed with the female B. sylvestris introduced into colony $\mathrm{Bt} 3$, and noticeable changes had occurred after just three hours had passed.

\section{DISCUSSION}

\subsection{Discrimination process and social cohesiveness}

This study showed that $B$. terrestris workers recognized and tolerated nestmates but expressed aggressive behaviours towards nonnestmates. This behaviour seemed to be correlated with variation in chemical cues among the colonies. We confirmed that $B$. terrestris colonies could be distinguished according to their chemical profiles, which was expected for bumblebees (Free, 1958, 1987). Benest (1972) had also hypothesised that odour was probably involved in recognition process according to his observations between one $B$. terrestris nest and intruders from some other species. It is supposed that in most social Hymenoptera, nestmate acceptance and aggression towards an intruder is the result of chemical discrimination (Bonavita et al., 1987; Breed and Bennett, 1987; Nowbahari et al., 1990). Nestmates would share a common odour according to the "gestalt model" (Crozier and Dix, 1979), consisting mainly of hydrocarbons present on the cuticle (Lahav et al., 1999; Singer, 1998; Soroker et al., 1994). When an individual's odour is detected, the profile will be compared to a reference model (or template) encoding nestmate chemical signatures. Individuals will be rejected if the chemical deviation from the reference reaches a threshold level (see for reviews Lenoir et al., 1999; Van der Meer and Morel, 1998). Our finding of a strong positive correlation between the degree of agonism and the extent of the difference in the chemical profiles of allocolonial workers in the intrusion and pairing experiments supports this model.

\subsection{Influence of comb}

B. terrestris workers did not defend their comb against alien conspecific workers in the test arena, except by buzzing, which is a weak agonistic behaviour (Duchateau, 1989). Removed from the social environment of the nest, the workers also may have been incited to tend comb (composed of brood and adhering brood pheromone components in the wax) (Heinrich, 1974), which stimulated brood care behaviours rather than triggered aggressiveness. Even allocolonial workers were attracted to this alien comb. However, alien B. terrestris workers 
were immediately detected as intruders when they entered an alien nest because of their chemical profiles, which presented different proportions of cues, compared to residents and nest environment.

The wax comb is a very important source of odorants for nestmate recognition in honey bees (Breed et al., 1995) and may provide a similar cue for bumblebees by enhancing their ability to identify invaders by amplifying the colony odour and reinforcing the recognition template. Queens and workers have glands in the ventral abdomen that secrete wax which is used to create comb and may contain odorants that contribute to the "gestalt" odour of the colony. In addition to contributing their own chemical signature, bumblebees may also actively acquire the odors of their nestmates. We observed that when comb was present in an arena, individuals rub the ventral side of their abdomen and sometimes their posterior legs against the comb, a behaviour similar to that of wax deposition. A bumblebee's hair is covered by a wax that could retain odorant molecules (Free, 1958). The hairs in the region of the abdomen where rubbing occurs are numerous and branched (unpublished data), increasing the total surface area for odorant transfer. We also observed an increase in self-grooming among these comb-rubbing individuals, which may have been used to spread the odorants over a greater part of the body surface. Nestmates could acquire this gestalt odour over time to better fit the identification reference template. For example, newly emerged workers of $B$. hypnorum have very low quantities of volatiles compounds compared to their queens and older workers, but they progressively acquire the colony odour and are accepted by resident workers (Ayasse et al., 1995). Also, newly emerged workers of B. terrestris are easily accepted into conspecific colonies (personal observation), probably because they do not possess many of the odorants that would identify them as foreign.

\subsection{Strategies used by the inquiline B. sylvestris}

In encounters with potential hosts, the $B$. sylvestris females did not aggressively react to attacks but tried to avoid any contact with workers attacking them. Avoidance was also used by $B$. sylvestris females during their initial introduction into the $B$. terrestris nest, although they responded more aggressively to attacks by these workers. Küpper and Schwammberger (1995) also found that $B$. sylvestris inquilines invaded nests of $B$. pratorum without aggression. The B. sylvestris female appeared to change her strategy when introduced into the $B$. terrestris colony. This strategy involved an active process that might have been a response to both the difference in the way these workers treated her (indeed B. pratorum and B. terrestris workers behaved differently) and her recognition that she was not in the nest of her natural host. Bombus vestalis, the natural inquiline of $B$. terrestris appeared to have evolved a very different intrusion strategy for dealing with its host species; it mauls host individuals to achieve reproductive dominance (Frehn and Schwammberger, 2001).

Chemical profiles of the inquilines indicated low amounts of cuticular compounds before their intrusion into a nest. The $B$. sylvestris females either have not yet synthesised the full complement of hydrocarbons or they produce a minimal quantity of these compounds. Thus these inquilines initially would be chemically "invisible" to facilitate their integration into a host nest (Lenoir et al., 1999, 2001). A similar discrete strategy was observed in workers of a ponerine ant, Ectatomma rui$d u m$, in which the reduction of cuticular compounds facilitated entry by thieves into another colony (Jeral et al., 1997). The B. sylvestris inquilines then acquired or produced the necessary odorants to facilitate their being acceptance into a host nest (Alford, 1975; Howard et al., 1990). This is a strategy used by newly mated queens of the ant Polyergus rufescens prior to their usurping a Formica nest (D'Ettore and Errard, 1998). Just five days later these ants are adopted by host individuals, large amounts of hydrocarbons are present on their cuticle with a composition similar to that of the host queen. In wasps, the obligatory social parasite, Polistes atrimandibularis, can sequentially change the composition of its chemical signature to control the host nest of P. biglumis bimaculatus (Bagnères et al., 1996). In the same way, B. sylvestris females introduced into a B.terrestris colony for 24 hours acquired similar quantities of compounds to those of the resident workers. Had 
the inquilines been allowed to stay longer, the chemical profiles of the B. sylvestris females might have more closely matched that of the host workers. B. sylvestris females could acquire colony odour by frequent contact with the colony comb, acquiring worker and queen odorants from the wax that they cannot produce themselves (Alford, 1975). However a more complete mimetism may only be possible when these inquilines nest with their natural host, $B$. pratorum. In this situation, $B$. sylvestris engaged in "head-rubbing", which consisted in moving close to a host bumblebee of B. pratorum and gently rubbing against her head or thorax (Küpper and Schwammberger, 1995). According to the authors, pheromonal communication for the establishing of dominance may be involved. A similar behaviour occurs in B. citrinus (Fisher, 1983c).

Regardless of the exact mechanism used, B. sylvestris inquilines have developed the ability to overcome the nestmate recognition capabilities of B. pratorum to diversify the resources of the host colony in support of their own reproduction. The strategy appears to be host specific, so that the proximal mechanisms allowing a successful intrusion may vary widely across species. The idea of comparing host-parasite interactions for normal and atypical hosts promises to reveal a lot about the mechanisms involved in integrating the parasite into the host colony. Nevertheless, a chemical study including B. pratorum workers and queens will be helpful to improve our understanding of its inquiline's usurpation strategy. Moreover, to fully understand the evolution of inquiline bumblebees and their place in bumblebee phylogeny, it will be necessary to study a wider range of host-inquiline species by looking at the before and after chemical profiles when parasitic females are introduced into colonies of different species. This and future studies of the inquilines will help to provide a basis for comparison and elucidation.

\section{ACKNOWLEDGEMENTS}

We are grateful to S. Iserbyt and J.-F. Godeau for their help in the bumblebee collection in the field. We thank A. Lenoir and A.-G. Bagnères for proofreading the manuscript, and two anonymous referees for constructive and helpful comments on this manuscript. We are grateful to C.S. Brent and P.A. Bankhead for editorial assistance.
Résumé - Inquilinisme chez Bombus (Fernaldaepsithyrus) sylvestris (Hymenoptera, Apidae) : analyses comportementales et chimiques des interactions hôte-parasite. Chez les bourdons, certaines espèces inquilines sont obligatoirement dépendantes de colonies hôtes appartenant à une autre espèce de bourdons. Les ouvrières de l'espèce hôte élèvent la descendance de l'inquiline tout en abandonnant parfois celle de leur reine. Le comportement de telles espèces parasites leur a valu le nom de « bourdons coucous ». Si nous considérons que les bourdons parasites et leurs hôtes ont évolué conjointement, comme c'est généralement le cas chez les autres Hyménoptères sociaux, une espèce d'inquiline devrait être phylogénétiquement proche de son espèce hôte. Au contraire, les espèces inquilines obligatoires de bourdons forment plusieurs sousgenres constituant un clade monophylétique et distinct au sein du groupe de Bombus comprenant en partie les espèces hôtes correspondantes. Mais comment les femelles inquilines parviennent-elles à être acceptées par leurs hôtes ? Le problème devient plus complexe quand on observe des espèces inquilines parvenant à entrer dans le nid hôte sans manifester ni induire de comportement agressif, malgré l'existence d'un système de reconnaissance élaboré. En effet, dans les sociétés d'Hyménoptères, ce système est basé sur la détection de composés chimiques lipidiques recouvrant la cuticule. Dans ce travail, nous avons étudié l'implication des signaux chimiques cuticulaires dans les processus de discrimination au sein des colonies de bourdons communs et leur utilisation dans l'intégration sociale des inquilines non agressives, telles que Bombus (Fernaldaepsithyrus) sylvestris Lepeletier. Après avoir réalisé une étude comportementale afin de tester la discrimination interindividuelle chez Bombus terrestris, nous avons analysé les profils chimiques cuticulaires de soies prélevées chez les individus de différentes colonies. Les résultats ont montré que les processus de discrimination sont corrélés aux signaux chimiques cuticulaires, ce qui confirme que les bourdons appartenant à la même colonie partagent une odeur commune. Puis, par une expérience d'intrusion d'une femelle inquiline dans un nid hôte ainsi que d'une série d'expériences de rencontres dyadiques, nous avons étudié le comportement de femelles $B$. sylvestris en présence d'hôtes soit naturel, $B$. pratorum, soit nonnaturel, $B$. terrestris. Les résultats ont montré que les inquilines semblent employer une stratégie discrète pour s'introduire dans une colonie hôte : elles ne sont pas agressives et possèdent peu de signaux chimiques sur leur cuticule, ce qui leur permettrait ne pas être discriminées comme étrangères par leurs hôtes naturels. Ensuite, ces femelles inquilines acquéraient assez rapidement une signature chimique similaire à celle de leur colonie hôte, ce qui faciliterait leur intégration dans le nid.

Bombus terrestris / inquilinisme / signature chimique / discrimination / stratégie non agressive 
Zusammenfassung - Kuckuckshummeln bei Bombus (Fernaldaepsithyrus) sylvestris Lepeletier (Hymenoptera, Apidae): Analyse von chemischen und Verhaltensinteraktionen zwischen Wirt und Parasit. Bei den Hummeln sind in Nester eindringende (inquiline) Bombus Arten obligatorisch auf heterospezifische Wirtskolonien angewiesen. Diese Kolonien ziehen dann die Nachkommen der Schmarotzer auf, gleichzeitig vernachlässigen sie manchmal die Nachkommen der eigenen Königin. Das Verhalten solcher parasitischen Arten hat ihnen den Namen „Kuckuckshummeln“ eingebracht. Wenn wir unterstellen, dass Hummelparasiten und Wirte eine gemeinsame evolutionäre Entstehung haben, so wie es gewöhnlich auch bei anderen Hymenopteren der Fall ist, sollte die inquiline Spezies ihrer Wirtsart phylogenetisch nahe stehen. Im Gegensatz hierzu bilden bei den Hummeln die inquilinen Arten verschiedene Untergattungen, die einen gesonderten und monophyletischen Kladus innerhalb der Gruppe Bombus bilden, der die korrespondierenden Wirtsarten nur teilweise einschließt. Aber wodurch gelingt es den inquilinen Weibchen von ihren Wirten angenommen zu werden? Das Problem wird dadurch noch komplexer, dass einige inquiline Arten keinerlei Aggression anwenden, um die Nester zu betreten. Das Erkennungssystem von Verwandten der Hymenopterensozietäten ist hochentwickelt, generell basiert es auf der Erkennung chemischer Komponenten auf der Kutikula. Wir untersuchten, ob kutikuläre chemische Kennzeichen an dem Unterscheidungsprozess in gewöhnlichen Hummelkolonien beteiligt sein könnten, und ob diese zur sozialen Integration nichtaggressiver Schmarotzer wie Bombus (Fernaldaepsithyrus) sylvestris Lepeletier angewendet werden könnten. Zunächst untersuchten wir die Nestgenossenerkennung in Völkern von Bombus terrestris und analysierten die kutikulären chemischen Profile von Haaren außerkolonialer Individuen. Die Ergebnisse zeigten, dass die Unterscheidungsprozesse mit kutikulären chemischen Kennzeichen korreliert waren. Dies bestätigte, dass die dem gleichen Volk angehörenden Hummeln einen gemeinsamen Duft teilten. Wir beobachteten das Eindringverhalten von Schmarotzerweibchen in ein Wirtsnest und das Verhalten von B. sylvestris Weibchen bei Versuchen in gepaarten Kombinationen von Weibchen der natürlichen und nicht-natürlichen Wirte $B$. pratorum L. und B. terrestris L. Die Kuckuckshummeln können unter Verwendung einer besonderen Strategie erfolgreich in eine Wirtskolonie eindringen: Sie verhalten sich weder aggressiv noch besitzen sie eine chemische Kennzeichnung. Sie werden daher von ihren Wirten nicht als fremd erkannt. Ein darauffolgender Erwerb einer der Wirtskolonie ähnlichen chemischen Kennzeichnung würde ihre weitergehende Integration in das Nest dann zusätzlich erleichtern.

Bombus sylvestris / Inquilinismus / Unterscheidungsprozess / chemische Kennzeichnung / nichtaggressive Strategie

\section{REFERENCES}

Alford D.V. (1975) Bumblebees, London, DaviesPoynter, $352 \mathrm{p}$.

Altmann J. (1974) Observational study of behavior: sampling methods, Behaviour 49, 228-265.

Ayasse M., Marlovits T., Tengö J., Taghizadeh T., Francke W. (1995) Are the pheromonal dominance signals in the bumblebee Bombus hypnorum L. (Hymenoptera, Apidae)? Apidologie 26, 163 180.

Bagnères A.-G., Lorenzi M.C., Dusticier G., Turillazzi S., Clément J.-L. (1996) Chemical usurpation of a nest by paper wasp parasites, Science 272, 889-892.

Benest G. (1972) Note préliminaire sur la réaction d'ouvrières de Bombus terrestris à la présence d'intruses, Insectes Soc. 19, 131-135.

Bonavita-Congourdan A., Clément J.-L., Lange C. (1987) Nestmate recognition: the role of cuticular hydrocarbons in the ant Camponotus vagus Scop, J. Entomol. Sci. 22, 1-10.

Breed M.D., Bennett B. (1987) Kin recognition in highly eusocial insects, in: Fletcher D.J.C., Michener C.D. (Eds.), Kin recognition in animals, John Wiley, pp. 243-285.

Breed M.D., Garry M.F., Pearce A.N., Hibbard B.E., Page R.E.J. (1995) The role of wax comb in honey bee nestmate recognition, Anim. Behav. 50, 489496.

Cederberg B. (1979) Doftstyrt värdval hos snylthumlor - Odour guided host selection in Psithyrus (Hym., Apidae), Entomol. Tidskrift 100, 128-129.

Cederberg B. (1983) The role of trail pheromones in host selection by Psithyrus rupestris (Hymenoptera, Apidae), Ann. Entomol. Fennici 49, 11-16.

Crozier R.H., Dix M.W. (1979) Analysis of two genetic models for the innate components of colony odor in social Hymenoptera, Behav. Ecol. Sociobiol. 4, 217-224.

D'Ettorre P., Errard C. (1998) Chemical disguise during colony founding in the dulotic ant Polyergus rufescens Latr. (Hymenoptera, Formicidae), Insects Soc. Life 2, 71-77.

Duchateau M.J. (1989) Agonistic behaviours in colonies of the bumblebee Bombus terrestris, J. Ethol. 7, 141-151.

Emery C. (1909) Über den Ursprung der dulotischen, parasitischen und myrmekophilen Ameisen, Biol. Zentralbl. 29, 352-362.

Fisher R.M. (1983a) Recognition of host nest odour by the bumble bee social parasite Psithyrus ashtoni (Hymenoptera: Apidae), J. N.Y. Entomol. Soc. 91, 503-507.

Fisher R.M. (1983b) Inability of the social parasite Psithyrus ashtoni to suppress ovarian development in workers of Bombus affinis (Hymenoptera, Apidae), J. Kans. Entomol. Soc. 56, 69-73. 
Fisher R.M. (1983c) Behavioural interactions between a social parasite Psithyrus citrinus (Hymenoptera: Apidae) and its bumble bees hosts, Proc. Entomol. Soc. Ont. 114, 55-60.

Fisher R.M. (1984) Dominance by a bumble bee social parasite (Psithyrus citrinus) over workers of its host (Bombus impatiens), Anim. Behav. 32, 304305.

Fisher R.M. (1985) Evolution and host specificity: dichotomous invasion success of Psithyrus citrinus (Hymenoptera: Apidae), a bumblebee social parasite in colonies of its two hosts, Can. J. Zool. 63, 977-981.

Fisher R.M. (1987) Queen-worker conflict and social parasitism in bumble bees (Hymenoptera: Apidae), Anim. Behav. 35, 1026-1036.

Fisher R.M. (1988) Observations on the behaviours of three European cuckoo bumble bee species (Psithyrus), Insectes Soc. 35, 341-354.

Fisher R.M., Greenwood D.R., Shaw G.J. (1993) Host recognition and the study of a chemical basis for attraction by cuckoo bumble bees (Hymenoptera: Apidae), J. Chem. Ecol. 19, 771-786.

Free J.B. (1958) The defence of bumblebee colonies, Behaviour 12, 233-242.

Free J.B. (1987) Pheromones of social bees, Chapman \& Hall London, University Press, Cambridge, 218 p.

Frehn E., Schwammberger K.H. (2001) Social parasitism of Psithyrus vestalis in Free-foraging Colonies of Bombus terrestris (Hymenoptera: Apidae), Entomol. Gen. 25, 103-105.

Heinrich B. (1974) Pheromone-induced brooding behavior in Bombus vosnesenskii and B. edwardsii (Hymenoptera: Bombidae), J. Kans. Entomol. Soc. 47, 396-404.

Howard R.W., Akre R.D., Garnett W.B. (1990) Chemical mimicry in an obligate predator of carpenter ants (Hymenoptera: Formicidae), Ann. Entomol. Soc. Am. 83, 607-616.

Jeral J.M., Breed M.D., Hibbard B.E. (1997) Thief ants have reduced quantities of cuticular compounds in a ponerine ant, Ectatomma ruidum, Physiol. Entomol. 22, 207-211.

Kistner D.H. (1979) Social and evolutionary significance of social insect symbionts, in: Hermann H.R. (Ed.), Social Insects, Vol. 1, London, Academic Press, pp. 339-413.

Küpper G., Schwammberger K.H. (1995) Social parasitism in bumble bees (Hymenoptera, Apidae): observations of Psithyrus sylvestris in Bombus pratorum nests, Apidologie 26, 245-254.

Lahav S., Soroker V., Hefetz A. (1999) Direct behavioral evidence for hydrocarbons as ant recognition discriminators, Naturwissenschaften 86, 246-249.

Lenoir A., Fresneau D., Errard C., Hefetz A. (1999) The individuality and the colonial identity in ants: the emergence of the social representation concept, in: Detrain C., Deneubourg J.L., Pasteels J. (Eds.), Information processing in social insects, Basel, Birkhäuser, pp. 219-237.
Lenoir A., D’Ettorre P., Errard C., Hefetz A. (2001) Chemical ecology and social parasitism in ants, Annu. Rev. Entomol. 46, 573-599.

Löken A. (1984) Scandinavian species of the subgenus Psithyrus Lepeletier (Hymenoptera: Apidae), Entomol. Scand., Suppl. 23, 1-45.

Lowe R.M., Ward S.A., Crozier R.H. (2002) The evolution of parasites from their hosts: intra- and interspecific parasitism and Emery's rule, Proc. R. Soc. Lond. B 269, 1301-1305.

Michener C.D. (2000) The Bees of the World, The Johns Hopkins University Press, Baltimore and London, 913 p.

Nowbahari E., Lenoir A., Clément J.-L., Lange C., Bagnères A.-G., Joulie C. (1990) Individual, geographical and experimental variation of cuticular hydrocarbons of the ant Cataglyphis cursor (Hymenoptera: Formicidae): their use in nest and subspecies recognition, Biochem. Syst. Ecol. 18, 63-73.

Oldham N.J., Billen J., Morgan E.D. (1994) On the similarity of the Dufour gland secretion and the cuticular hydrocarbons of some bumblebees, Physiol. Entomol. 19, 115-123.

Pedersen B.V. (1996) A phylogenetic analysis of Cuckoo Bumblebees (Psithyrus, Lepeletier) and Bumblebees (Bombus, Latreille) inferred from sequences of the mitochondrial gene cytochrome oxydase 1, Mol. Phylogenet. Evol. 5, 289-297.

Rasmont P., Ebmer P.A., Banaszak J., van der Zanden G. (1995) Hymenoptera Apoidea Gallica. Liste taxonomique des abeilles de France, de Belgique, de Suisse et du Grand-Duché de Luxembourg, Bull. Soc. Entomol. Fr. 100, 1-98.

Schmid-Hempel P. (1998) Parasites in Social Insects, Princeton Univ. Press., 409 p.

Schwarz M., Gusenleitner F., Westrich P., Dathe H.H (1996) Katalog der Bienen Österreichs, Deutschlands und der Schweiz (Hymenoptera, Apidae), Entomofauna (Ansfelden), Suppl. 8, 1-398.

Siegel S., Castellan N.J. (1956) Nonpararametric statistics for the behavioral sciences, Mc Graw-Hill Int. (Ed.), 399 p.

Singer T.L. (1998) Roles of hydrocarbons in the recognition systems of insects, Am. Zool. 38, 394405.

Soroker V., Vienne C., Hefetz A., Nowbahari E. (1994) The postpharyngeal gland as a "gestalt" organ for nestmate recognition in the ant Cataglyphis niger, Naturwissenschaften 81,510-513.

Van der Meer K.R., Morel L. (1998) Nestmate recognition in ants, in: Van der Meer R.K., Breed M.D., Winston M., Espelie C. (Eds.), Pheromone communication in social insects: ants, wasps, bees and termites, Westview Press, Boulder, CO, pp. 79 103.

Van Honk C., Röseler P.-F., Velthuis H., Malotaux M. (1981) The conquest of a Bombus terrestris colony by a Psithyrus vestalis female, Apidologie 12, 57-68. 
Vergara C., Schröder S., Almanza M.T., Wittmann D. (2001) Suppression of ovarian development in bumblebee workers by Bombus queens and parasitic Psithyrus females, in: Menzel R., Rademacher E. (Eds.), Proc. 2001 Berlin Meeting of European Sections of IUSSI, $251 \mathrm{p}$.

Wcislo W.T. (1987) The roles of seasonality, host synchrony, and behaviour in the evolutions and distributions of nest parasites in Hymenoptera (Insecta), with special reference to bees (Apoidea), Biol. Rev. 62, 515-543.

Williams P.H. (1994) Phylogenetic relationships among bumble bees (Bombus Latr.) a reappraisal of morphological evidence, Syst. Entomol. 19, 327-344.

Williams P.H. (1998) An annotated checklist of bumble bees with an analysis of patterns of description (Hymenoptera: Apidae, Bombini), Bull. Nat. Hist. Mus., Entomol. Ser. 67, 79-152.

Wilson E.O. (1971) The Insect Societies, Harvard Univ. Press, Cambridge, Mass, 548 p.

Zimma B.O., Ayasse M., Tengö J., Ibarra F., Schulz C., Francke W. (2003) Do social parasitic bumblebees use chemical weapons? (Hymenoptera, Apidae), J. Comp. Physiol. A 189, 769-775. 